\title{
Evaluation of financial investment risk of enterprises
}

\author{
Jiangwei $\mathrm{Ni}^{1}$ \\ ${ }^{1}$ Guangzhou Polytechnic Normal University,Guangdong,China,510540
}

\begin{abstract}
Based on the current situation of enterprise financial investment risk management, this paper first analyzes the overview of enterprise financial investment risk assessment basis, then introduces the relevant influencing factors of enterprise financial investment risk assessment, and finally combines qualitative and quantitative concepts with specific investment situation to establish risk In order to enhance the quality and effect of enterprise financial investment risk assessment, the purpose is to provide reference for relevant research.
\end{abstract}

\section{Introduction}

Most enterprises in China will be challenged by the risk in the process of investment risk assessment, and financial investment evaluation plays an important role. During the period of investment risk assessment, if we can think about the risk assessment system and get scientific and accurate evaluation results, we can skillfully avoid risks and create more economic benefits for enterprises. From the perspective of financial investment, there are many changes in the market environment. If effective measures are not timely selected to avoid risks, the financial risks of enterprises will be induced. Based on this new period, enterprises should carry out risk assessment to lay a solid foundation for the healthy operation of enterprises.

\section{An overview of the assessment basis of enterprise financial investment risk}

\subsection{Assessment objectives}

The risk caused by financial investment is inevitable. The risk problems existing in many investment projects are called general phenomenon and universal phenomenon, which means that the corresponding projects will face corresponding risk challenges. Investment risk also has randomness, that is, the random risk brought by investment projects to investors. Therefore, scientific risk assessment should be carried out before the beginning of investment to control the occurrence of blind investment [1]. The traditional concept lacks the meaning of risk assessment. Investors invest projects based on their own experience and luck. This kind of investment mode is relatively subjective. However, investors always have a relatively vague idea about the amount of money finally obtained, which affects the quality of risk management without introducing the concept of risk assessment. At present, people find the means to deal with the risk in the process of investment. They can invest in the risk directly or indirectly. Therefore, it is necessary to solve the investment risk fully, and then implement the risk assessment objectives.

\subsection{The risk forms of financial investment.}

First, the types of derivative financial assets investment. Derivative financial assets are mainly a form derived from the premise of all-round development of the financial industry, which has a certain financial nature and develops into a novel investment structure in the era. However, compared with securities investment, derivative financial assets investment, basic investment and even securities investment, the investment risk is relatively large, which is also the project with the greatest risk in all investment systems. First of all, in the process of investment in derivative financial assets, it is necessary to control the operation of the existing funds of the enterprise, indicating that the effect of the derivative financial funds in controlling the enterprise's capital adjustment will result in the limitation of the enterprise's cash flow and increase the economic burden; secondly, if the enterprise introduces the means of derivative financial investment, it may affect the asset value to a great extent, and the risk assessment is not in place Finally, the concrete operation will increase the probability of risk and is not conducive to the acquisition of comprehensive benefits of enterprises.

Second. Interest rate risk type. The so-called interest rate risk, that is, the potential risk generated by the change of interest rate. In the structure of the market economy system, it is found that the economy in many fields of society changes on the same day, and the existing interest rate changes of banks will lead to changes in economic loans and loans, corresponding to changes in the stock fund industry, leading to the decrease of the overall interests of enterprises and companies. From the perspective of social finance research, if the overall interest rate of an enterprise rises, the value of corresponding investment financial assets will decrease. If the value of financial assets is reduced, the interest rate growth will be naturally controlled, and all factors will 
affect the asset value. Therefore, in the interest rate risk control within the market, we should consider the relevant factors and select effective means to optimize and Prevention [3].

\section{Related factors of financial investment risk assessment}

Risk identification is the premise of scientific risk management, and corresponding operational measures should be selected. Only by finding out the objective factors of the risk and monitoring the financial investment risk at all times can we show the effectiveness in the guidance of the risk plan and in fact. Based on the overall practice, the risk factors include:

First, the products are cumbersome. With the gradual extension of technical functions, the complicated logic problems of product $\mathrm{R} \& \mathrm{D}$, testing and maintenance appear imperceptibly. The development of new technology leads to the increase of program code and the difficulty of product test and installation, which leads to investment risk; secondly, the complexity of risk management. Under the restriction of market, environment and policy, product performance is continuously enhanced. However, due to the mutual influence of these three points [4], strict requirements for product standardization, shortening development cycle and test production cycle lead to difficulties in investment risk management; thirdly, new scientific and technological progress. Under the background of many technological innovation, some enterprises carry out the production according to the "customized" production requirements. This kind of technological innovation affects the technological innovation environment of developers, and brings risk impact for quantitative products and largescale application; fourthly, the level of human resources is limited. All products in the R \& D and testing production process should be strongly supported by workers, as the main factor of product success and failure. Different employees should carry out different operations in the product life cycle. People's knowledge and technical experience will have certain risks. Therefore, in the management of financial investment risk, we should think about the risk related factors Avoid financial investment risks [5].

\section{The effective strategy of enterprise financial investment risk assessment}

\subsection{High quality evaluation means}

First, the basic idea of risk assessment. On the whole, there are three ways to evaluate the financial investment risk of enterprises. The first is the mean variance evaluation. This method is used to evaluate the deviation of the expected return of financial investment and predict the loss of the investment income. The larger the variance value is, the greater the investment risk index is; the second is the value risk assessment, which has a significant feature, that is, the measurement of the maximum loss value In other words, the index can accurately indicate the actual risk degree of financial assets. The larger the index is, the greater the investment risk is. Therefore, the enterprise should complete the evaluation task through the index during the risk assessment period.

Second, the actual measurement of financial investment risk. Risk measurement takes the previous information as the research premise, evaluates the corresponding investment risk and generates losses according to the probability theory. For the financial investment risk assessment, in fact, it analyzes the loss caused by financial investment by means of probability calculation. There are two kinds of loss frequency estimation. First, the probability distribution theory is used to sort out the previous data information to obtain the empirical loss distribution information, and then the probability of risk occurrence is evaluated around the distribution state. Secondly, the information loss is regarded as the basis to form a probability distribution table. If the information is accurate, the evaluation result will be more reliable.

\subsection{Improve the effectiveness of financial risk assessment}

Firstly, combining with the specific investment situation, the qualitative and quantitative concepts are integrated. To evaluate the financial investment risk of different industries, we can choose which kind of investment means. To evaluate the financial investment risk of the same type of industry, there will be some differences among the three evaluation methods, which need to be deeply compared and selected. It can be said that the index method emphasizes the risk of the overall change of the investment market in the evaluation, and is more inclined to the systematic risk measurement. Therefore, if the enterprise pays more attention to the response of a single investment target to the overall operation of the market, it can be ranked by the index [7]. At the same time, the integration of qualitative and quantitative concepts, for the actual evaluation of financial investment risk, we should introduce qualitative and quantitative ideas. During the study of investment risk, we should first make qualitative judgment, including risk graphic evaluation, risk degree assessment and risk management score. Moreover, risk graphic evaluation is to present the possibility of financial investment risk generation. In the process of qualitative evaluation, risk graph is used to evaluate the risk of financial investment The most common application.

Second, establish risk management system and strengthen risk assessment. In enterprise management, managers should have a certain sense of risk control, and the establishment of risk prevention and control mechanism should highlight the scientific nature, such as the establishment of a special risk management unit, the implementation of purposeful standardized management operations, and the operation and management mechanism of enterprises should ensure the scientificity of investment decisions. Combined with the enterprise's own perspective, the risk early warning mechanism should be constructed around the specific situation to ensure that it can timely 
predict the potential investment risk, ensure that the enterprise's decision-making level is enhanced, and the loss caused by the investment risk is controlled in the corresponding range. The construction of the risk early warning system should keep pace with the times and be combined with the information system to complete the investment risk information management And early warning. Managers should strengthen risk assessment and give risk assessment during the specific financial investment period. Risk management is the key to risk management. It serves as the basis for enterprise decisionmaking and is closely related to investment return. Therefore, the adverse factors of financial investment are comprehensively controlled to reduce investment losses, so as to ensure the standardized allocation between investment risk and return and keep pace with the times Make decisions and control economic losses.

Third, control the risk classification and set up a highquality risk management team. In the process of enterprise development, human resource is the main content of core competitiveness. From the perspective of scientific control of investment risk, it is important to establish a highquality risk management team. Organize regular training for investors, extend the ways and means of training, and set up knowledge training activities of different categories and levels. And appropriate employment of outstanding graduates, into the fresh blood of financial investment, transformation of the investment management team. Carry out the corresponding assessment work, form a reward and punishment mechanism, and mobilize the initiative and enthusiasm of employees in the enterprise [8]. In terms of financial investment, the market nature and categories are quite different, which leads to obvious risk differences, so the forecasting and management methods are also different. Therefore, enterprises should classify the existing investment risks and control the risk probability purposefully. In particular, different types of products should be selected scientifically and efficiently to make the investment portfolio reasonable. Before the investment starts, we should integrate the changes of interest rate and market, and set up emergency plans for the risks to ensure the effective return on investment.

\section{Conclusion}

To sum up, the management of enterprise financial investment risk is a key topic. The management of financial investment risk not only affects the pace of sustainable development of enterprises, but also relates to the acquisition of economic benefits of enterprises. In the new period, managers of all enterprises should pay close attention to financial investment risk control and choose practical measures to optimize financial investment links, such as combining with specific investment situation, In order to maximize the efficiency of financial investment and ensure the healthy and long-term operation and operation of enterprises, we should integrate qualitative and quantitative concepts, establish a risk management system, strengthen risk assessment, control risk classification, and establish a high-quality risk management team.

\section{Project information}

This research achievement has been supported by the Institute level key discipline project of Applied Economics, Tianhe college, Guangdong Normal University of Technology: the importance of financial investment management in enterprise management and its application analysis (Project No.: yjz201901).

\section{References}

1. Wei Zhichi. On the technology and application of enterprise financial investment risk assessment [J]. Mall modernization, 2019, 000 (006): 93-94

2. Gao Xi. How to reasonably evaluate the bond investment risk of small and medium-sized financial enterprises [J]. China foreign investment, 2019, 430 (07): 84-86

3. Wei Dong, Zhuang Junmin, Meng Defeng. Optimization of risk enterprise value evaluation based on option pricing theory [J]. Foreign trade, 2018, 000 (006): 155-156

4. $\mathrm{Li}$ Chao. Countermeasures against financial investment risks in enterprise financial management [J]. Taxation, 2019

5. Cao Jinfei. Application of logistic regression model in financial investment risk evaluation [J]. Statistics and management, 2018, 254 (09): 24-26

6. Yu Wansu, Qu Jingyi, Wang Jintao. Venture capital risk assessment based on BP neural network [J]. Brand research, 2018, 000 (006): p.105-107

7. Wu Jiangong, Huang Xingxin. Personnel risk assessment of transnational investment of Chinese enterprises based on BP network [J]. Financial economics, 2018, 498 (24): 70-73

8. He Rui. Analysis of the impact of international environment on venture capital assessment of hightech enterprises in China [J]. Business information, 2018, 000 (041): 117 